\title{
Introduction, Breeding and Poaching of Scarlet Macaws (Ara macao L.) in a Temperate Country: A Case Study from The Netherlands
}

\author{
R.M.V. Jonker ${ }^{*}, 1,2$ and W.L.M. Tamis ${ }^{2}$ \\ ${ }^{I}$ City Parrots, Groenoordstraat 35, 2316 AZ Leiden, The Netherlands \\ ${ }^{2}$ CML, Institute of Environmental Sciences, Leiden University, P.O. Box 9518, 2300 RA Leiden, The Netherlands
}

\begin{abstract}
Poaching for the pet bird trade is one of the main threats to wild parrots. Parrots in urban areas might be exempt from poaching because nests are likely inaccessible in the urban mosaic of public and private lands where the public and authorities keep more effective vigilance than in natural habitats. We report on the demographics and fate of a small population of exotic Scarlet Macaws (Ara macao L.) introduced into the urban area of Haarlem in The Netherlands in the 1970's, which has a temperate, maritime climate, quite unlike the natural breeding area of the species. One breeding pair was reported, with successful breeding attempts in at least eight years between 1980 and 2009. A series of poaching events between 2005 and 2009 likely lead to the demise of the local nesting population of Scarlet Macaws.
\end{abstract}

Keywords: Poaching, Exotic species, Establishment, Breeding success, Ara macao, Parrot.

\section{INTRODUCTION}

Parrots are the most threatened family of birds. Of the 372 species the IUCN Red List of Threatened Species lists 17 as Critically Endangered (Cr), 34 as Endangered (En) and 45 as Vulnerable $(\mathrm{Vu})$ [1]. Parrots suffer from the combined effects of habitat destruction, agricultural conflict and both legal and illegal trade. In the wild bird trade it is common practice to remove parrot nestlings from the nesting cavity. Rare species fetch the highest prices on both the national and international markets [2]. In The Netherlands the price for a pair of Scarlet Macaws (Ara macao L.) e.g. is about $€ 3250$ [3].

Trade and captive breeding of parrots have made them common pets in countries where they do not naturally occur. Some of these birds have escaped or been set free, as is evident by the numerous introduced populations of parrots around the world far from their natural ranges or even climate zones [4]. Surprisingly, even threatened species are among these introduced populations: e.g. Critically Endangered Lesser Sulphur Crested Cockatoos (Cacatua sulphurea) have had a sizable population in Hong-Kong for many decades [5] and several taxa of threatened Amazona species live in the cities of Southern California [6]. These introduced populations predominately live in urban and suburban areas [4]. It's been suggested that parrots suffer less from nest poaching in urban areas because the mosaic of public and private lands make many nests unavailable to poachers and both the public and authorities keep more effective vigilance over this illegal practice [7]. Here we report on a population of introduced Scarlet Macaws in an

*Address correspondence to this author at the CML, Institute of Environmental Sciences, Leiden University, P.O. Box 9518, 2300 RA Leiden, The Netherlands; Tel: +31 (0)71 527744 7479/5140506; Fax: +31 (0)71 527 7434; E-mail: director@cityparrots.org urbanized area in The Netherlands that has suffered several poaching events.

\section{INTRODUCTION AND FIRST BREEDING, 1970 TO 2004}

The presence of Scarlet Macaws in The Netherlands can be traced back to the beginning of the 1970's when several parrot species (including Scarlet Macaws) were kept at liberty on a petting farm just outside Haarlem $\left(52^{\circ} 23^{\prime} 02^{\prime \prime} \mathrm{N}\right.$, $4^{\circ} 35^{\prime} 53^{\prime \prime E)}[8,9]$. The first successful breeding of Scarlet Macaws near Haarlem occurred in 1980 and 1981 at a petting farm [10], (Table 1). In 1983 breeding was reported, as "yearly production of young", at Elswout, an estate near Haarlem [9].

Birds exhibited breeding behaviour in 1992, 1994 and 2003, although nesting was not confirmed (Table 1). It was not documented if the Scarlet Macaws were or were not breeding in the intermittent years. During the 1980's a mixed flock of up to 11 Scarlet and 2 Blue-and-gold Macaws (Ara ararauna) frequented the area and where observed in the city of Haarlem and Bloemendaal $[8,9,11]$ (pers. comm. Brandwijk). The two Blue-and-gold Macaws never bred and were more tame then the free-roaming Scarlet Macaws (pers. com. Brandwijk). Several other species of smaller psittacines did join the flock but no records of species or breeding were made. After the death of the owner of the petting farm in 1990 the big flock of macaws rapidly declined with only a few remaining. We speculate that most of the macaws that still roosted at the farm at that point were sold by the owner's widow when the petting farm closed. De Nobel [8, 9] did not report any poaching attempts, but dead Scarlet Macaws were reported as a consequence of predation by goshawk (Accipiter gentilis) and of a collision with a train. We are unaware of other observations of escaped, released or breeding Scarlet Macaws in other parts of The Netherlands $[8,9,11]$. 
Table 1. Breeding of Scarlet Macaw, Ara macao L., near Haarlem, The Netherlands, Including Indications of Poaching. Sources: 1980, 1981, 1983: [8-10], 2005-2009: own research. Breeding indications: $b b=b r e e d i n g ~ b e h a v i o r, ~ e=e g g(s), ~ n=n e s t l i n g(s)$, $\mathrm{f}=$ fledgling(s), $\mathrm{t}=$ territories $\mathbf{y}=$ young (nestling or fledgling). The highest breeding score is presented. At Tuindorp the nests were inspected for eggs and young. Nest inspection was not possible at nests Elswout site 1 and 2 . Breeding event are of one pair; when a spring clutch failed the pair often re-clutched in summer

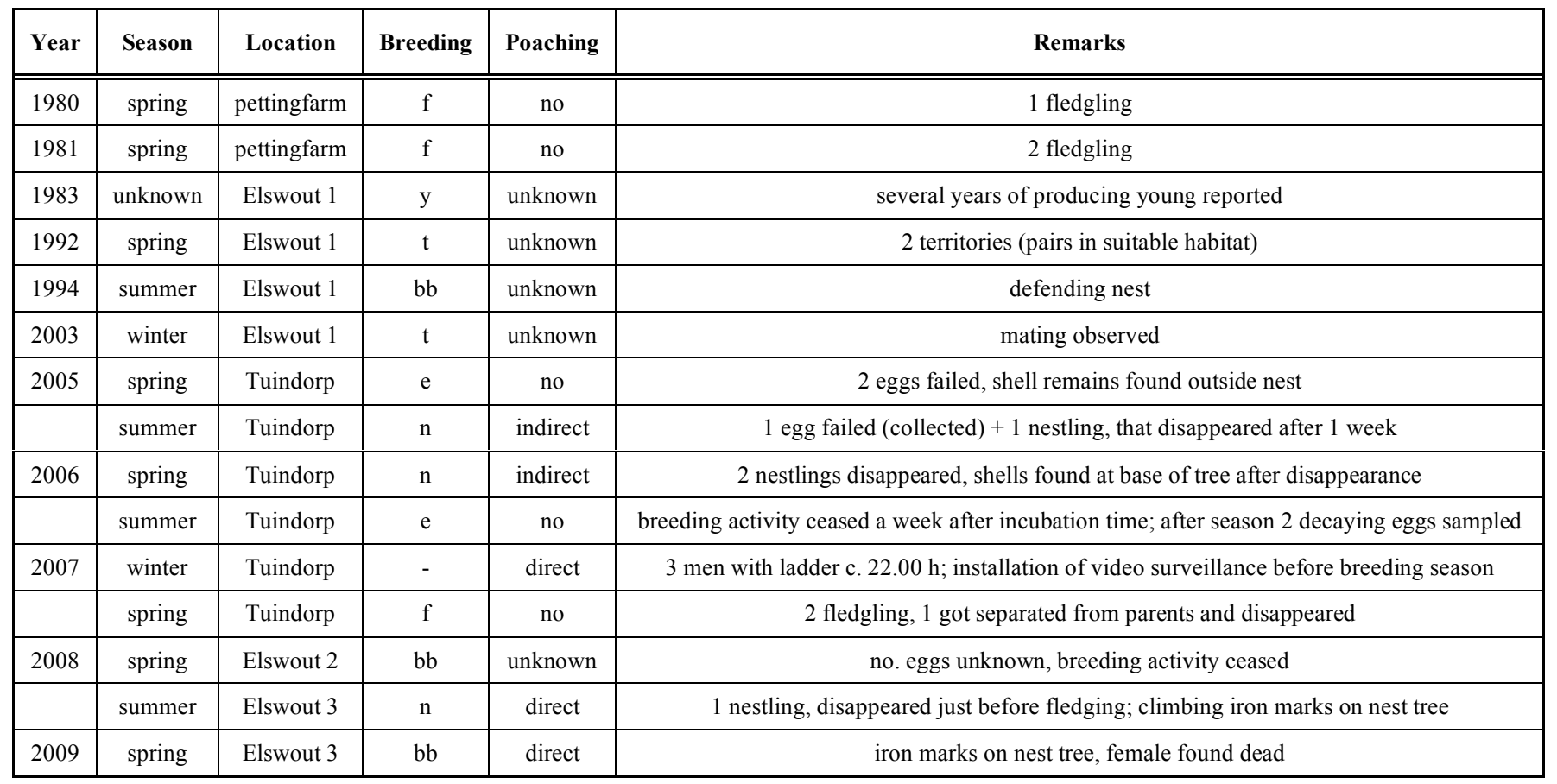

\section{PERSISTENCE, BREEDING AND POACHING BETWEEN 2005-2009}

In March 2005, two Scarlet Macaws were located by the first author at Elswout. The typical broad yellow band and absence of much green on the wings of these macaws make it probable that they belonged to the rare Central American subspecies Ara macao cyanoptera. The pair observed was different (based on colour patterns) from that reported at the same location in the 1980's. The macaws still used the farm where they, or there ancestors, were kept at liberty to get food. They visited the farm from January till the end of the breeding season (August). There they were fed bread with margarine or peanut butter, table scraps and sunflower seeds. Although their nutritional intake at the farm was substantial we observed them foraging in the wild in every season of the year. In winter their staple diet where seeds taken from the kernels of various pine trees. In autumn till January their favourite were Taxus baccata seeds, rejecting much of the fruit, in spring they also foraged on the flowers of this pine. Other regularly utilised food sources where: European beech nuts (Fagus sylvatica), Elderberry (Sambucus nigra), Common hornbeam seeds (Carpinus betulus), Field Maple seeds (Acer campestre), fruits of Thuja spec. and various fruits like cherries, apples and plums. Also a variety of blossoms and buds. Like macaws in Central and South America the Scarlet Macaws [12] in The Netherlands where regularly observed eating dirt (geophagy) and dead wood.

From 2005 till 2008 there was evidence of breeding by Scarlet Macaws (nesting behaviour or the presence of eggs, nestlings or fledglings) at either Tuindorp or one of two nests at nearby Elswout. Only in 2007, when protected by camera surveillance, were there two successful fledglings (Fig. 1), in other years nests failed.

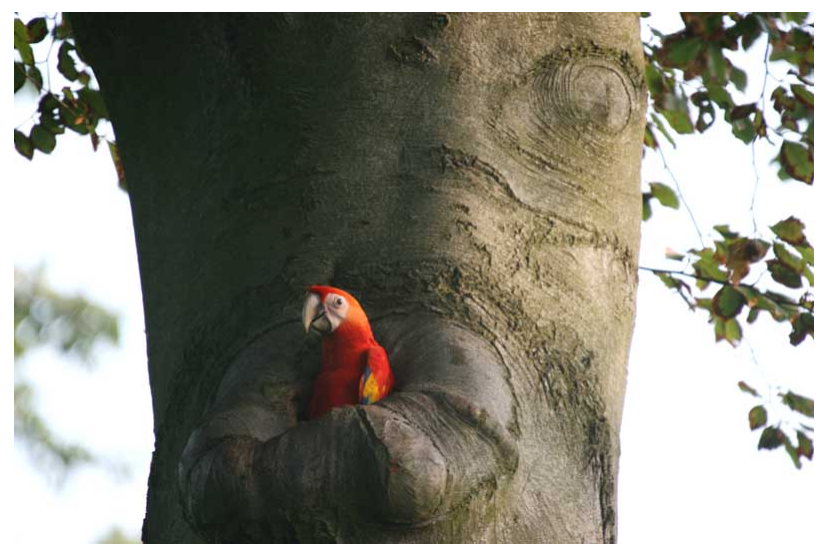

Fig. (1). Youngest nestling of 2007 looking outside the nest, shortlybefore leaving it (Photo: RMV Jonker). Download: http://www.flickr.com/photos/parrots/4408873530/sizes/o/in/set72157623435579623/

Each year between 2005 till 2009 there were indirect or direct indications of poaching (Table 1). Indirect indications for poaching are disappearance of nestlings, followed by days of intensive searching behaviour by the parents, indicating a sudden event separated them from their offspring (Fig. 2). Predation was not likely as chicks where too large for avian predators present and no scratch marks where found typical of predation by European Pine Marten (Martes martes). 


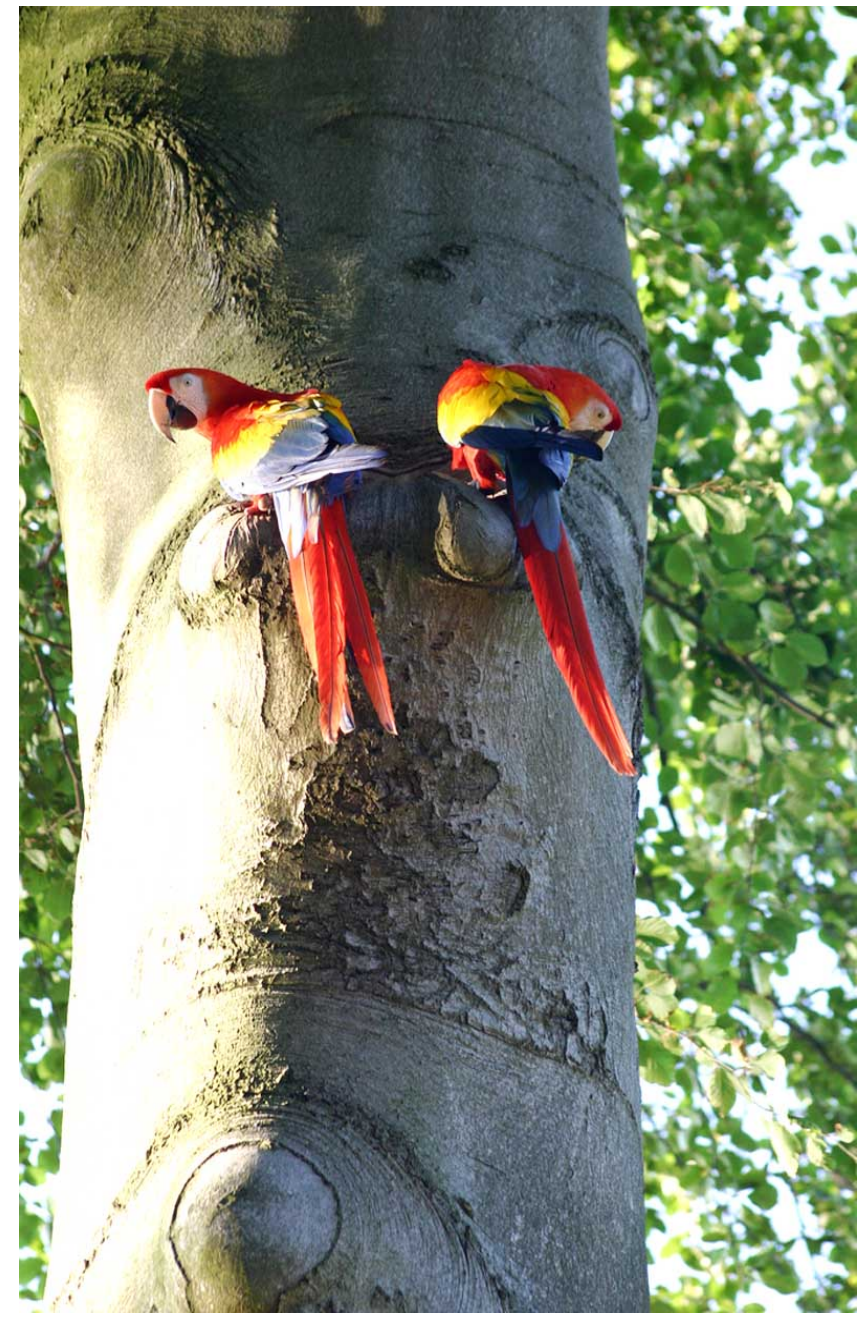

Fig. (2). Pair at their nest in 2006 after the disappearance of their young. They repeatedly checked their empty nest, as shown in the picture, for several days (Photo: RMV Jonker). Download: http://www.flickr.com/photos/parrots/4696118073/sizes/l/

Direct observations of poaching were first made an evening in the winter of 2007 when three men were found climbing the nest tree with a ladder. A member of the public stopped them in their activities. Other indirect observations were climbing iron marks (Fig. 3) on the empty nesting tree in 2008 and 2009.

In the spring 2009 the female was found dead near the nest in the midst of breeding season, with an injury to her beak. She probably died, when the poachers tried to catch the birds on the nest. The skin is now archived in the Netherlands Centre for Biodiversity-Naturalis museum at Leiden.

\section{DISCUSSION}

It is remarkable how Scarlet Macaws are able to survive and breed in the Netherlands, which is in a completely different climate zone and habitat (broad leafed deciduous forest) type then their (presumably) Central and South American homelands. The Netherlands has a maritime climate, with cool summers and mild winters. The average

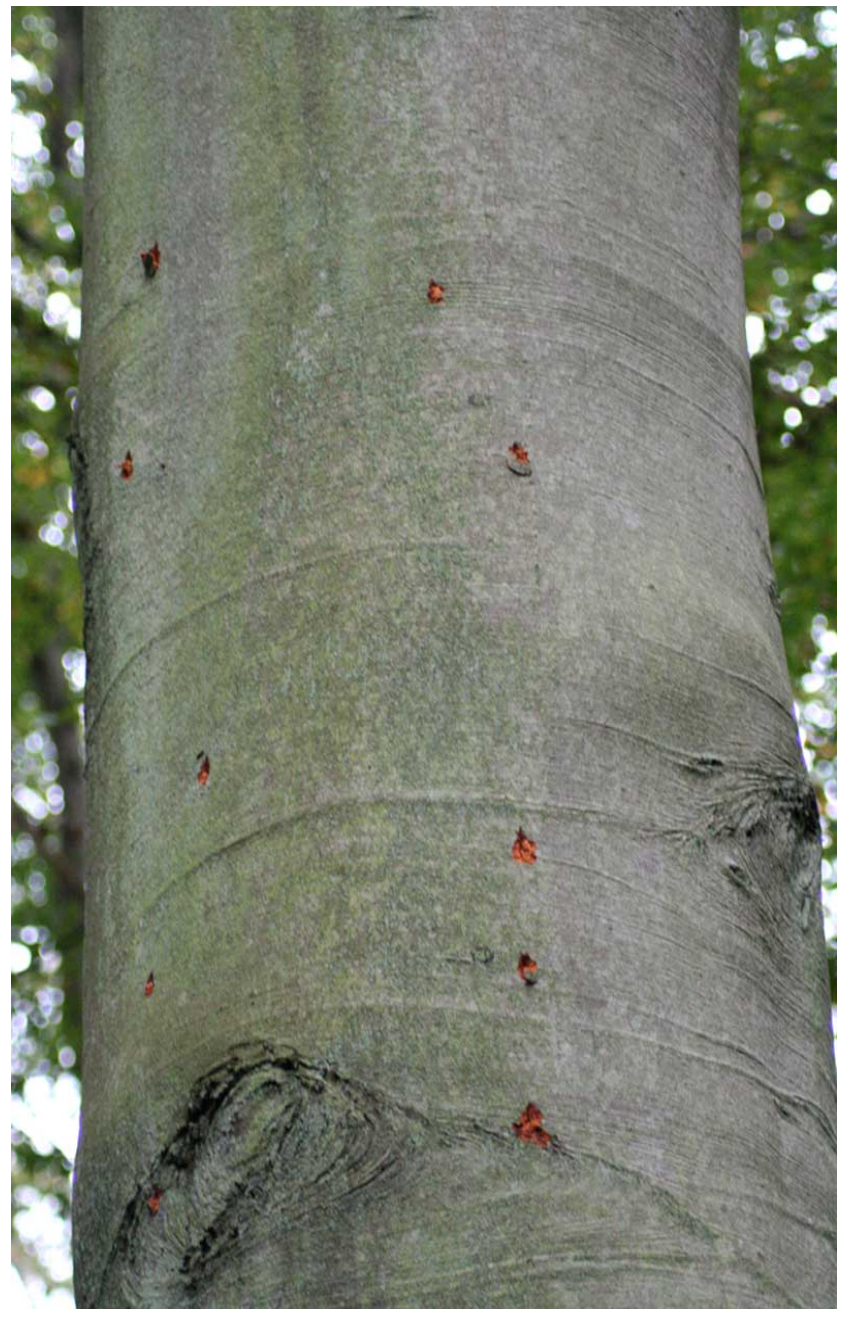

Fig. (3). Marks from climbing irons after the 2008 nestling disappeared (Photo: RMV Jonker). Download: http://www.flickr. com/photos/parrots/4409219222/sizes/1/in/set-

$72157623560384116 /$

temperature is $2^{\circ} \mathrm{C}$ in January and $19^{\circ} \mathrm{C}$ in July, with an annual average of about $10^{\circ} \mathrm{C}$. Average annual rainfall is approximately $765 \mathrm{~mm}$. Scarlet Macaws usually reside in Central and South America. Their lowland forest habitat in Costa Rica is characterized by heavy rains (up to 5000 $\mathrm{mm} /$ year) and a mean annual temperature of $27^{\circ} \mathrm{C}$. Scarlet Macaws are also introduced and breeding in Medellin, Colombia [13]. This population was released from the Santa $\mathrm{Fe}$ zoo in the 1980's. The climate and habitat conditions at Medellin (average annual temperature and rainfall $21,7^{\circ} \mathrm{C}$ $1586 \mathrm{~mm}$, elevation $1,495 \mathrm{~m}$ ) are also different from their original habitats. Since the 2007 study photographic evidence and newspaper reports indicate several Scarlet Macaws fledge annually in Medellin. Perhaps one factor that makes Scarlet Macaws in Medellin successful is the use of walled-in secure living areas as breeding areas. These compounds may also keep poachers at bay.

This Medellin population is increasing in contrast to the Haarlem population, which is now technically extinct with no females left. The documented fertility of the Macaws is however comparable to that found for Scarlet Macaws in Peru [14]. If the Haarlem Macaws had been exempt from 
poaching, they may have been able to build up a true population certainly as the macaws as adults seem to be capable to persist in the wild in The Netherlands for over a decade.

Despite repeated pleas with the forestry department that manages Elswout no protective measures were taken. Although no official statement was made, informal talks made it clear they did not want to spend their resources on protecting an exotic species. However all wild birds in The Netherlands are protected, so disturbing of nests is strictly prohibited, regardless if the species is native or not. Some bird species can be hunted in The Netherlands but no parrots feature on these lists. Scarlet Macaws also enjoy protection trough CITES appendix 1 [15] which prohibits the possession and transport of this species, or parts thereof, without certain permits. Given these facts the Scarlet Macaws should have been given better protection from these illegal practices on forestry department lands. Although the macaws were regularly observed feeding and socialising in the centre of Haarlem their choice of breeding at the edge of the city on forestry department lands likely made them more vulnerable to poaching. At night the nesting area was accessible to poachers, so they were not protected by public vigilance that benefits most other urban parrot populations. When camera surveillance for the protection of the Tuindorp nest was available and made public via a website the Macaws were able to fledge two chicks. These aids of the modern era are becoming readily available and relatively cheap. In many instances camera networks, like local law enforcement networks or traffic cameras, are available in the urban setting or can be extended to the locations needed. Simply advertising that camera surveillance is used to protect nesting urban parrot populations might be all that is needed to keep breeding parrots safe from nest poaching.

Another conservation matter is that the free-ranging macaws from the petting farm resulted in a small but locally adapted population. Free-flight bird shows are popular features of a modern zoo visit. Keeping a threatened parrot species at liberty on zoo grounds, preferably in areas within their native ranges, would be a cost effective and engaging way of obtaining breeding stock suitable for reintroduction.

\section{ACKNOWLEDGEMENT}

We like to acknowledge Grace Innemee, Wouter Teunissen, Wim Teeuwen \& the Tegel family for their support in this project.

\section{CONFLICT OF INTEREST}

None declare.

\section{REFERENCES}

[1] IUCN Red list of threatened species. Version 2009; 1: vs.: 27-9. http://www.iucnredlist.org

[2] Wright TF, Toft CA, Enkerlin-Hoeflich, E. et al. Nest poaching in neotropical parrots. Conserv Biol 2002; 15: 710-20.

[3] Parkietensociëteit, Richtprijzen 2009/2010.2010: http://www parkietensocieteit.nl/richtprijzen.php .

[4] Butler CJ. Feral parrots in the continental United States and United Kingdom: Past, present, and future. J Avian Med Surg 2005; 19(2): 142-9.

[5] Reinschmidt M. Gelbwangenkakadus in Hongkong. Papageien 1999; 2: 64-8.

[6] Mabb KT. Naturalized (wild) parrots in California: a current assessment: 2002: Proceedings of The Gabriel Foundation third annual symposium: Parrots in the New Millennium 2002; 7-10. California.

[7] Beissinger SR, Snyder NFR, Ed. New World parrots in crisis, Washington DC, Smithsonian Institution Press 1992; 165-200.

[8] SOVON Vogelonderzoek, Ed. Atlas van de Nederlandse Broedvogels Nederlandse fauna deel 5, Nationaal Natuurhistorisch Museum Naturalis, KNNV Uitgeverij \& European Invertebrate Survey Nederland, Leiden 2002.

[9] De Nobel P. De Geelvleugelara's van Elswout en wijde omgeving. Fitis 2002; 38(5): 19-21.

[10] Panorama, Sanoma Uitgevers BV. 1981 nr. 53; 31 Dec. 42-3.

[11] Waarneming. nl Ara macao 2010. http://waarneming.nl/soort/ view/1417.

[12] Lee ATK, Kumar S, Brightsmith DJ, Marsden SJ. Parrot claylick distribution in South America: do patterns of "where", help answer the question "why"? Ecography 2009; 32: 1-11.

[13] Lara-Vásquez CE, Castaño-Rivas AM, Jonker RMV. Notasacerca de lasguacamayas (Psittacidae: Ara) introducidas en el municipio de Medellín, Colombia. Boletín SAO 2007; XVII: 104-10.

[14] Vigo G, Williams M, Brightsmith DJ. Growth of Scarlet Macaw (Ara macao) chicks in southeastern Peru. Neotrop Ornithol 2011; 22: 143-53.

[15] UNEP-WCMC Checklist of CITES species (CD-ROM). CITES Secretariat, Geneva, Switzerland, and UNEP-WCMC, Cambridge, United Kingdom 2008. 